\title{
SINTESIS BAHAN UBAHAN GRADUAL ALUMINUM TITANAT/KORUNDUM DARI ALUMINA TRANSISI DENGAN PENAMBAHAN MgO
}

\author{
Achmad Sulhan Fauzi \\ Suminar Pratapa (suminar.pratapa@physics.its.ac.id) \\ Mohammad Herman Eko Santoso \\ Jurusan Fisika, Fakultas Matematika dan IImu Pengetahuan Alam \\ Institut Teknologi Sepuluh Nopember
}

\begin{abstract}
This article describes the results of research on the use of transition alumina for improving the performance of ceramics. Synthesis has been made of gradual changes materials (Functionally Graded Materials, FGM) aluminum titanate (AT) / corundum based on transition alumina powders with the addition of $\mathrm{MgO}$ as a stabilizer of AT as much as 2 wt.\%. Samples without the addition of $\mathrm{MgO}$ was also made for comparison. Transition alumina with and without the addition of $\mathrm{MgO}$ were calcined at a temperature of $1100^{\circ} \mathrm{C}$ for 1 hour to become $\alpha$-alumina. The powder mixture was compacted at a pressure of $49.3 \mathrm{MPa}$ and then prasintered at a temperature of $1100^{\circ} \mathrm{C}$ for 1 hour, then repeatedly infiltrated with infiltrator TiCl3 solution (20\%) which prepared by dissolving the Ti metal powders into $\mathrm{HCl}$. Furthermore, the material sintered at temperatures of $1500^{\circ} \mathrm{C}$ with a holding time for 3 hours. Physical character of materials showed an increase in density and decrease in porosity of the material due to the addition of $\mathrm{MgO}$. Phase identification results obtained from the content of AT and corundum phases which gradual in depth, indicating that FGM has been formed. These results were supported by analysis of $x$-ray diffraction pattern showing the formation of a solid solution Al2 (1-x) + MgxTi1 xO5 which marked by the shifting of the peak of AT phase in FGM samples with the addition of MgO.
\end{abstract}

Keywords: alumina transition, aluminum titanate, FGM, solid solution

\begin{abstract}
ABSTRAK
Tulisan ini menjelaskan hasil penelitian tentang penggunaan alumina transisi untuk meningkatkan performa keramik. Telah dilakukan sintesis bahan ubahan gradual (Functionally Graded Material, FGM) aluminum titanat (AT)/korundum berbahan dasar serbuk alumina transisi dengan penambahan MgO sebagai penstabil AT sebanyak 2 wt.\%. Sampel tanpa tambahan MgO juga dibuat sebagai pembanding. Alumina transisi dengan dan tanpa penambahan $\mathrm{MgO}$ dikalsinasi pada temperatur $1100^{\circ} \mathrm{C}$ selama 1 jam sehingga menjadi a-alumina. Serbuk campuran dikompaksi pada tekanan 49,3 MPa lalu diprasinter pada temperatur $1100^{\circ} \mathrm{C}$ selama 1 jam, kemudian diinfiltrasi secara berulang dengan infiltran larutan $\mathrm{TiCl}_{3}(20 \%)$ yang dibuat dengan cara melarutkan serbuk logam Ti ke dalam $\mathrm{HCl}$. Selanjutnya bahan disinter pada temperatur $1500^{\circ} \mathrm{C}$ dengan holding time selama 3 jam. Karakterisasi fisik bahan memperlihatkan adanya kenaikan densitas dan penurunan porositas bahan akibat penambahan MgO. Dari hasil identifikasi fasa didapatkan kandungan fasa AT dan korundum yang gradual terhadap kedalaman, menunjukkan bahwa FGM telah terbentuk. Hasil ini didukung dengan analisis pada pola difraksi sinar-x yang
\end{abstract}


memperlihatkan terbentuknya larutan padat $\mathrm{Al}_{2(1-x)} \mathrm{Mg}_{x} \mathrm{Ti}_{1+x} \mathrm{O}_{5}$ yang ditandai terjadinya pergeseran puncak fasa AT pada sampel FGM dengan penambahan MgO.

Kata kunci: alumunium titanat, alumina transisi, FGM, larutan padat

Aluminum titanat (AT) adalah keramik dengan beberapa keunggulan sifat, di antaranya kapasitas panas yang baik, konduktivitas panas yang rendah, tahan korosi, bisa sebagai isolator, semikonduktor, konduktor, superkonduktor, keras dan kuat. Namun bahan keramik juga mempunyai keterbatasan, di antaranya adalah rapuh dan mempunyai ketahanan kejutan termal dan mekanik yang rendah sehingga menyebabkan terjadi retakan pada permukaannya (Suasmoro, 2000).

Material baru dengan desain komposisi gradual, biasa disebut FGM (Functionally-Graded Material), telah banyak dibuat. Salah satunya adalah FGM AT/korundum yang disintesis dengan metode infiltrasi berulang (Pratapa \& Low, 1998; Weddakarti, 2010; Pratapa dkk, 2011) dengan bahan dasar korundum yang relatif mahal sebagai matriksnya.

Tulisan ini mengangkat hasil riset penggunaan alumina transisi yang relatif lebih ekonomis sebagai bahan dasar matriks FGMs AT/korundum (Sari, 2010). Untuk meningkatkan performa termomekanik, seperti pada penelitian sebelumnya (Umaroh 2009; Weddakarti, 2010; Pratapa dkk., 2011), ditambahkan MgO sebanyak $2 \%$ sebagai penstabil AT karena dapat terdekomposisi menjadi korundum dan rutil pada temperatur $800-1280^{\circ} \mathrm{C}$ (Huang, Senos \& Baptista, 1996).

\section{METODE}

Alumina transisi terdiri atas fasa-fasa a-alumina (PDF 42-1468), $\beta$-alumina (PDF 10-0414) dan k-alumina (PDF 08-0013) seperti ditunjukkan pola difraksi bahan tersebut pada Gambar 1, kemudian setelah dikalsinasi pada temperatur $1100^{\circ} \mathrm{C}$ selama 1 jam menjadi korundum (10-0173) seperti diperlihatkan pada Gambar 2.

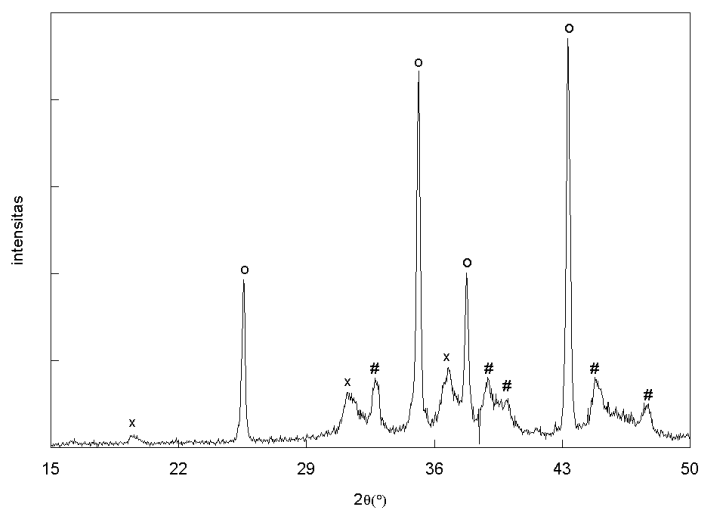

Gambar 1. Pola difraksi sinar- $x\left(\lambda_{\text {cu Ka }}=1,5418 \AA\right)$ alumina transisi. (o= $\alpha$-alumina; $x=\beta$-alumina; $\#=k$-alumina) 


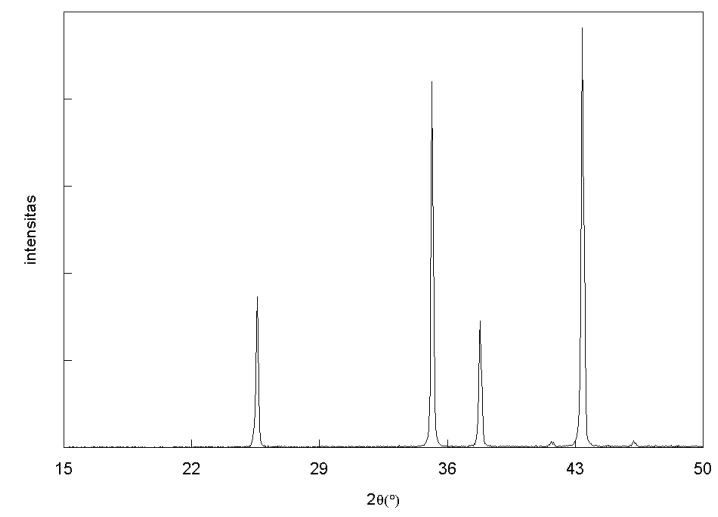

Gambar 2. Pola difraksi sinar-x ( $\lambda_{\text {cu Ka }}=1,5418 \AA$ ) a-alumina (korundum) hasil kalsinasi alumina transisi pada temperatur $1100^{\circ} \mathrm{C}$ selama 1 jam

Sintesis FGM dengan penambahan MgO diawali dengan pencampuran serbuk Alumina transisi tersebut dengan serbuk MgO (2 wt.\%), pencampuran dilakukan dengan penggerusan kemudian ditambahkan aquabidestilata dan larutan $\mathrm{NH}_{4} \mathrm{OH}$ dengan perbandingan $\mathrm{NH}_{4} \mathrm{OH} 10 \%$ dari aquabidestilata. Aquabidestilata ditambahkan langsung saat penggerusan, baru kemudian larutan $\mathrm{NH}_{4} \mathrm{OH}$ ditambahkan dengan diteteskan sambil terus digerus sampai tercampur merata, kemudian dilakukan pemanasan pada temperatur $1100^{\circ} \mathrm{C}$ untuk menghasilkan korundum (Sari, 2010).

Proses selanjutnya sampel dikompaksi dengan tekanan sekitar $49 \mathrm{MPa}$ sehingga terbentuk pelet berbentuk silinder dengan diameter sekitar $13 \mathrm{~mm}$ dan tebal $3 \mathrm{~mm}$. Selanjutnya sampel diprasinter pada temperatur $1100^{\circ} \mathrm{C}$ selama 1 jam agar lebih kuat dan tidak rapuh saat diinfiltrasi.

Selanjutnya dilakukan infiltrasi berulang menggunakan larutan $\mathrm{TiCl}_{3}(20 \%)$ sebanyak 5 kali. Sebelum proses infiltrasi, ditentukan nilai porositas dan densitasnya menggunakan metode Archimedes. Sampel yang telah diinfiltrasi disinter pada temperatur $1500^{\circ} \mathrm{C}$ selama 3 jam.

Uji fisik dilakukan setelah sinter untuk melihat perubahan massa, densitas, porositas serta penyusutan volum sampel, kemudian dilanjutkan dengan uji XRD pada permukaan sampai kedalaman 0,4 mm untuk mengetahui fasa-fasa yang terkandung dan kegradualan sampel. Analisis kuantitatif menggunakan High Score Plus dilakukan untuk mencari komposisi masing-masing fasa dalam sampel dan metode Rietveld digunakan untuk menentukan volum sel satuan masing-masing fasa. Semua perlakuan tersebut juga dilakukan pada sampel AT (FGM tanpa penambahan MgO), sehingga diketahui bagaimana pengaruh penambahan MgO pada FGM AT.

\section{HASIL DAN PEMBAHASAN}

Hasil karakterisasi fisik menunjukkan densitas dan porositas sampel FGMs AT dengan $0 \mathrm{wt} . \% \mathrm{MgO}$ yang relatif lebih besar dari pada sampel FGM AT dengan 2 wt.\% MgO setelah disinter pada temperatur $1500^{\circ} \mathrm{C}$, yaitu $13,8 \%$ dan $3,51 \mathrm{gr} / \mathrm{cm}^{3}$ untuk sampel AT, 10,5\% dan 3,49 gr/cm 3 untuk sampel ATM, seperti diperlihatkan pada Tabel 1. Pada penelitian yang lain (Fauzi, 2012), terjadi penurunan porositas dan kenaikan densitas bahan FGM akibat kenaikan temperatur sinter dari $1450^{\circ} \mathrm{C}$ ke $1550^{\circ} \mathrm{C}$. Kalita dan Somani (2010) juga melaporkan kenaikan temperatur sinter menyebabkan penurunan porositas. 
Tabel 1. Perubahan Densitas dan Porositas Sampel FGM AT dan ATM

\begin{tabular}{ccccc}
\hline Sampel & $\mathrm{P}_{0}(\%)$ & $\begin{array}{c}\mathrm{D}_{0} \\
\left(\mathrm{gr}_{\mathrm{cm}}\right)\end{array}$ & $\mathrm{P}_{\mathrm{i}}(\%)$ & $\begin{array}{c}\mathrm{D}_{\mathrm{i}} \\
\left(\mathrm{gr}_{\mathrm{cm}} \mathrm{cm}^{3}\right)\end{array}$ \\
\hline AT & 60,0 & 3,37 & 13,8 & 3,51 \\
ATM & 58,6 & 3,31 & 10,5 & 3,49 \\
\hline
\end{tabular}

Keterangan:

Po : Porositas sebelum sinter

Do : Densitas sebelum sinter

$\mathrm{Pi} \quad$ : Porositas setelah sinter

Di : Densitas setelah sinter

AT : FGMs AT tanpa MgO

ATM : FGMs AT dengan aditif 2 wt.\% MgO

Setelah disinter, di dalam sampel AT terdapat fasa AT (PDF 41-0258) dan terdapat fasa korundum (PDF 46-1212). Untuk sampel ATM terdapat fasa AT (PDF 09-0252) dan fasa korundum (PDF 11-0661). Kegradualan komposisi korundum dan AT terhadap kedalaman dapat dilihat dari pola-pola difraksi sinar-x pada kedalaman 0,0-0,4 mm untuk sampel AT dan ATM seperti disajikan pada Gambar 3.

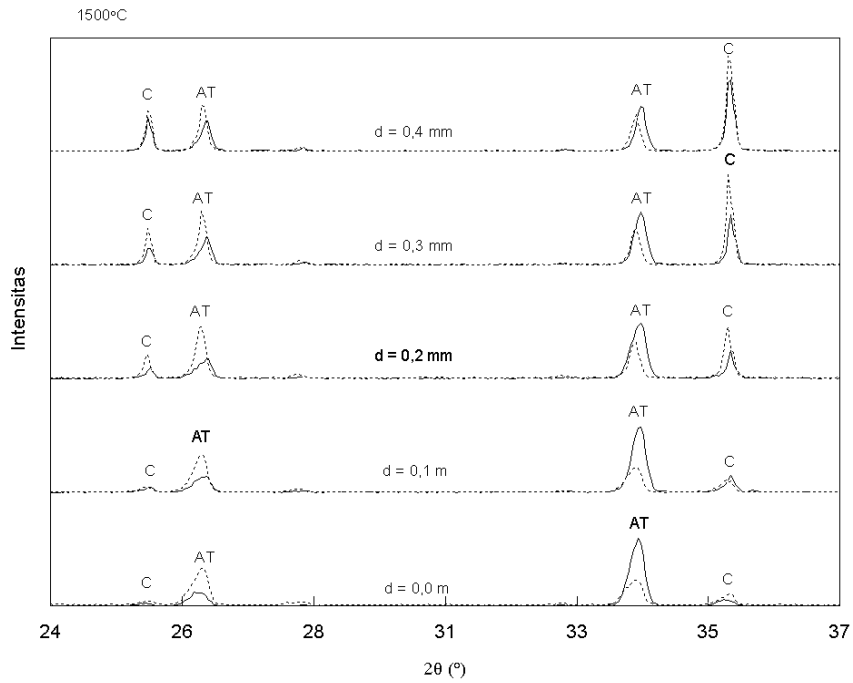

Gambar 3. Pola-pola difraksi sinar-x menunjukkan pergeseran puncak dan kegradualan fasa AT (garis penuh: AT; garis putus-putus: ATM) setelah disinter pada temperatur $1500^{\circ} \mathrm{C}$ selama 3 jam

Bila diamati lebih seksama, pada Gambar 3 tampak puncak AT sampel AT (pola garis putusputus) berada pada sekitar sudut $2 \theta=18,8^{\circ} ; 26,5^{\circ}$ dan $33,6^{\circ}$ bergeser sedikit ke kiri menjadi di sekitar sudut $2 \theta=18,6^{\circ} ; 26,4^{\circ}$ dan $33,5^{\circ}$ pada sampel ATM (pola garis penuh). Pergeseran puncak intensitas fasa AT ini juga diikuti perubahan lebarnya yang mengindikasikan terbentuknya larutan padat $\mathrm{Al}_{2(1-x)} \mathrm{Mg}_{x} \mathrm{Ti}_{1+x} \mathrm{O}_{5}$. Pergeseran puncak ini juga dilaporkan oleh Abdullah (2011) dan Pratapa dkk. (2011), tidak terbentuknya fasa spinel $\left(\mathrm{MgAl}_{2} \mathrm{O}_{4}\right)$, rutil $\left(\mathrm{TiO}_{2}\right)$ dan periklas $(\mathrm{MgO})$ merupakan indikasi reaksi yang sempurna dari prekursor yang terinfiltrasi dengan korundum sebagai matriksnya 
karena substitusi sebagian ion $\mathrm{Al}^{3+}$ dan $\mathrm{Ti}^{4+}$ dengan ion $\mathrm{Mg}^{2+}$ akibat penambahan aditif $\mathrm{MgO}$ karena jari-jari ion $\mathrm{Mg}^{2+}(0,66 \AA)$ dan $\mathrm{Ti}^{4+}(0,68 \AA)$ lebih besar daripada $\mathrm{Al}^{3+}(0,55 \AA)$ sehingga terbentuk larutan padat. Bukti lain terbentuknya larutan padat ini adalah terjadinya ekspansi volum AT pada sampel ATM akibat penambahan MgO karena ukuran ion $\mathrm{Mg}^{2+}$ yang relatif lebih besar dari $\mathrm{Al}^{3+}$, seperti ditunjukkan oleh Gambar 4.

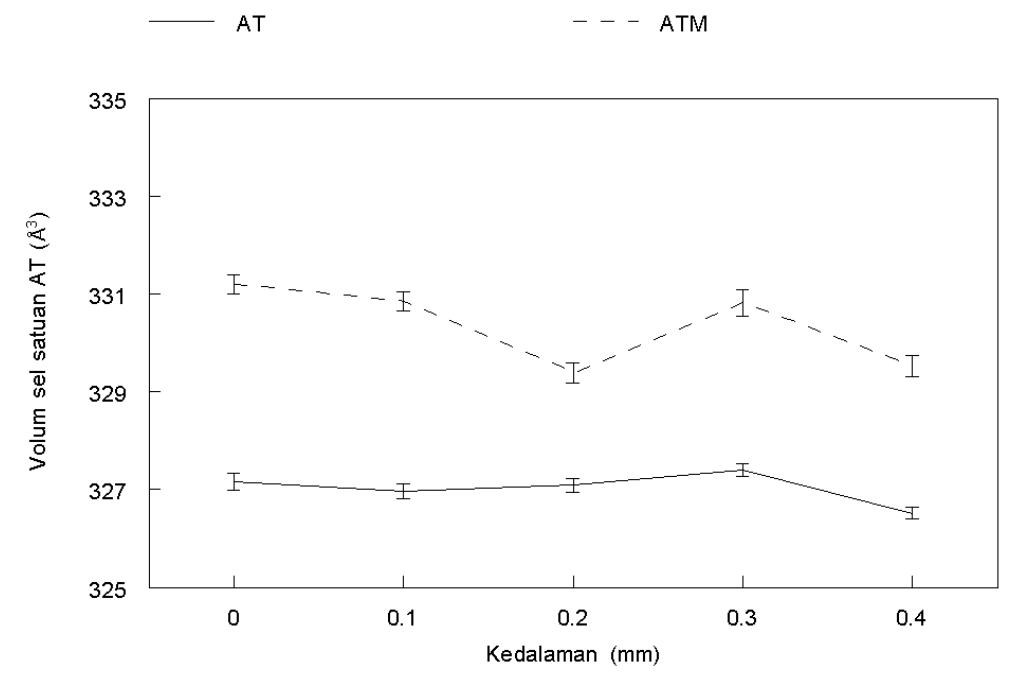

Gambar 4. Volum sel satuan AT dan ATM yang ditentukan dengan metode Rietveld pada permukaan sampai kedalaman $0,4 \mathrm{~mm}$. (garis penuh: AT; garis putus-putus: ATM).

Pada Gambar 3 tampak kandungan fasa AT mendominasi di permukaan sampel dengan komposisi yang gradual terhadap kedalaman. Puncak korundum (C) semakin tinggi dan puncak AT menurun terhadap kedalaman. Hasil analisis kuantitatif komposisi fasa seperti ditunjukkan dalam grafik fraksi volum relatif AT dan korundum pada Gambar 5, di permukaan terdapat fasa AT sebesar $71,8 \%$ yang turun menjadi $31,3 \%$ pada kedalaman $0,4 \mathrm{~mm}$, sebaliknya untuk fasa korundum dipermukaan terdapat $28,2 \%$ naik menjadi $68,7 \%$ pada kedalaman $0,4 \mathrm{~mm}$ dengan nilai gradien penurunan AT sebesar 9,92. Pada penelitian yang lain (Fauzi, 2012), penurunan fasa AT terhadap kedalaman pada sampel ATM menjadi semakin landai seiring kenaikan temperatur sinter, yaitu dengan nilai gradien 11,5 pada temperatur sinter $1450^{\circ} \mathrm{C}$ menjadi 8,2 pada temperatur sinter $1550^{\circ} \mathrm{C}$. Demikian juga untuk sampel AT, terjadi penurunan fasa AT terhadap kedalaman dengan nilai gradien 13,4 pada temperatur sinter $1450^{\circ} \mathrm{C}$ menjadi 9,3 pada temperatur sinter $1550^{\circ} \mathrm{C}$ (Santoso, 2011). Dari hasil tersebut dapat diduga kenaikan temperatur sinter menyebabkan distribusi fasa AT relatif lebih teratur terhadap kedalaman. Menurut Buscaglia dkk. (1994), kenaikan temperatur sinter, menyebabkan aditif MgO semakin larut dalam AT membentuk larutan padat. Selain itu juga akibat substitusi ion-ion $\mathrm{Mg}^{2+}$ terhadap sebagian ion-ion $\mathrm{Al}^{3+}$ dan $\mathrm{Ti}^{4+}$ semakin bertambah sehingga terjadi pengurangan porositas karena pertumbuhan butir. 


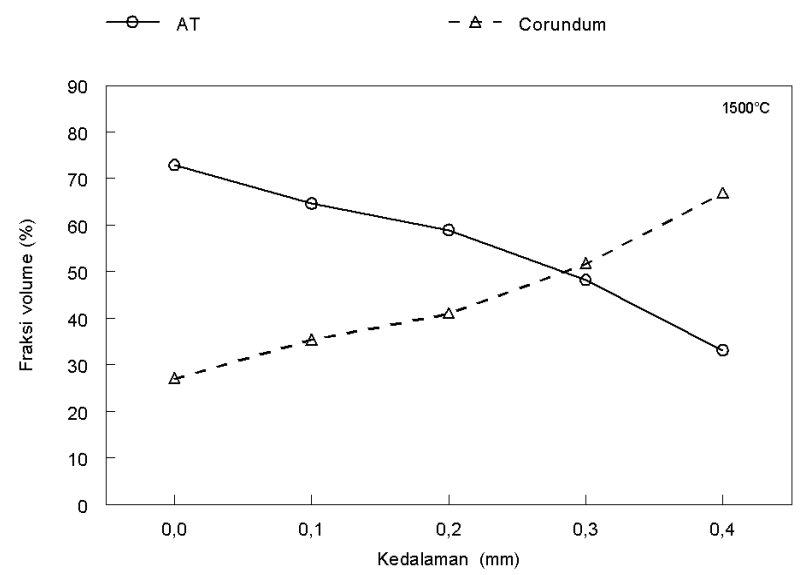

Gambar 5. Fraksi volum relatif AT dan korundum sampel FGMs ATM dengan temperatur sinter $1500^{\circ} \mathrm{C}$ pada kedalaman $0,0-0,4 \mathrm{~mm}$

Pemetaan unsur-unsur menggunakan SEM-EDX menunjukkan bahwa dalam sampel terdapat Al, Ti, O dan Mg pada permukaan FGMs AT dengan penambahan 2 wt.\% MgO seperti terlihat pada Gambar 6 dan 7. Terbentuknya larutan padat $\mathrm{Al}_{2(1-x)} \mathrm{Mg}_{\mathrm{x}} \mathrm{Ti}_{1+\times} \mathrm{O}_{5}$ dapat dikenali dari munculnya unsur-unsur $\mathrm{Al}, \mathrm{Ti}, \mathrm{Mg}$ dan $\mathrm{O}$, sedang daerah yang mengandung Al dan $\mathrm{O}$ saja merupakan butir korundum. Hasil tersebut sesuai dengan beberapa penelitan sebelumnya, Umaroh (2009), Weddakarti (2010), Abdullah (2011) dan Pratapa dkk. (2011) yang melaporkan bahwa penambahan 2 wt.\% MgO pada FGMs ATM menyebabkan terbentuknya larutan padat akibat bereaksinya $\mathrm{MgO}$ dengan korundum dan rutil.

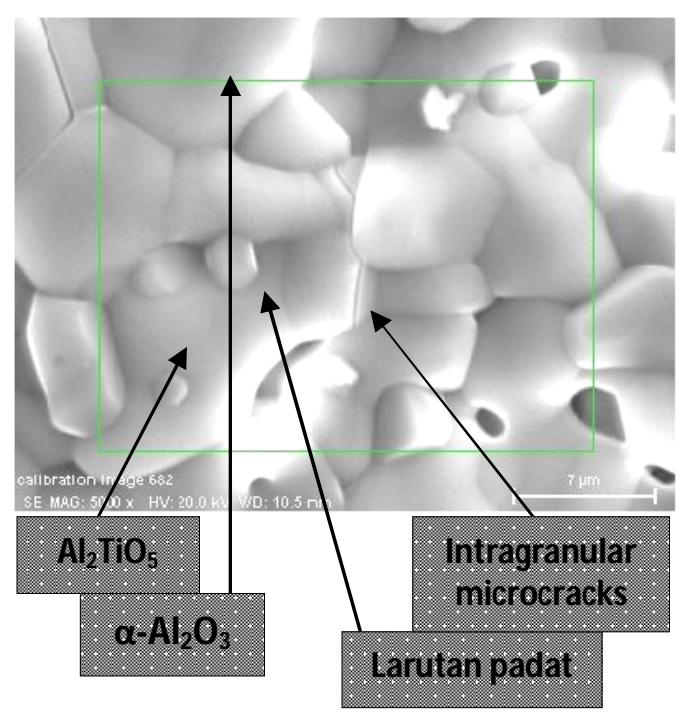

Gambar 6. Mikrostruktur hasil pengamatan SEM 


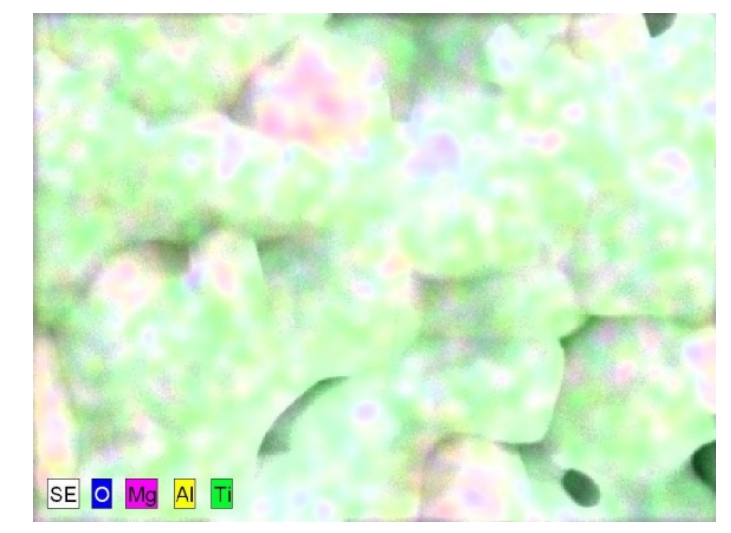

\author{
Gambar 7. Hasil pemetaan \\ unsur-unsur menggunakan EDX pada permukaan ATM
}

\title{
KESIMPULAN
}

Alumina transisi dapat disintesis menjadi FGM AT setelah disinter $1500^{\circ} \mathrm{C}$. Terbentuknya larutan padat $\mathrm{Al}_{2(1-x)} \mathrm{Mg}_{\mathrm{x}} \mathrm{Ti}_{1+\mathrm{x}} \mathrm{O}_{5}$ terdeteksi pada sampel dengan penambahan $2 \mathrm{wt} \% \mathrm{MgO}$ ditandai terjadinya pergeseran puncak fasa AT dan meningkatnya volum sel satuan AT dan didukung oleh hasil pengamatan mikrostruktur dan pemetaan unsur-unsur menggunakan SEM-EDX.

\section{REFERENSI}

Abdullah, D.D.P. (2011). Studi ekspansi termal keramik padat $A l_{2(1-x)} M g_{x} T i_{1+x} O_{5}$. Tesis master yang tidak dipublikasikan. Surabaya: Jurusan Fisika-FMIPA, ITS.

Buscaglia, V., Nanni, P., Battilana, G., Aliprandi, G., \& Carry, C. (1994). Reaction sintering of aluminium titanate: I-Effect of MgO addition. Journal of the European Ceramic Society, 13, 411-417.

Fauzi, A.S., (2012), Sintesis dan karakterisasi termomekanik FGMs berbasis aluminum titanat berbahan dasar alumina transisi. Tesis master yang tidak dipublikasikan. Jurusan FisikaFMIPA, Surabaya.

Huang, Y.X., Senos, A.M.R., \& Baptista, J.L. (1996). Effect of excess $\mathrm{S}_{i} \mathrm{O}_{2}$ in the reaction sintering of alumunium titanate-25 vol\% mullite composite. Ceramics International, 24, 223-228.

Kalita, S. J., \& Somani, V. (2010). $\mathrm{Al}_{2} \mathrm{TiO}_{5}-\mathrm{Al}_{2} \mathrm{O}_{3}-\mathrm{TiO}_{2}$ nanocomposite: Structure, mechanical property and bioactivitystudies. Materials Research Bulletin, Vol. 45, 1803-1811.

Pratapa, S., Low, \& I.M. (1998). Infiltration-Processed, functionally graded aluminum titanate/ zirkonia-alumina composite part II mechanical properties. Journal of Material Science, 33, 3047-3053.

Pratapa, S., Fauzi, A.S, \& Santoso, M.H.E. (2011). Microstructural and decomposition rate studies of periclase-added alumunium titanat-corundum functionally-graded materials. Material Letters, $11,72$.

Sari, T.K. (2010). Karakterisasi kegradualan komposisi FGMs korundum-rutile-alumunium titanat berbahan dasar alumina transisi. Tugas Akhir. Surabaya: Institut Teknologi Sepuluh Nopember.

Suasmoro. (2000). Fisika keramik. Surabaya: Jurusan Fisika FMIPA ITS. 
Umaroh, K. (2009). Sintesis FGM a-Al2O3/Al2TiO5-Distabilisasi-MgO dengan metode Infiltrasi Berulang. Tesis master yang tidak dipublikasikan. Surabaya: Institut Teknologi Sepuluh Nopember.

Weddakarti, E. (2010). Karakterisasi mikrostruktur dan kekerasan FGMs a-Al2O3/Al2TiO5distabilisasi-MgO hasil infiltrasi berulang. Tesis master yang tidak dipublikasikan. Surabaya: Institut Teknologi Sepuluh Nopember.

Wohlfromm, H, Thierry E, Pilar P, Jose S.M, \& Gareth T. (1991). Microstuctural characterization of aluminum titanatebased composite materials. Journal of the European ceramic society, 7 , 385-396. 